\title{
SIFAT-SIFAT DAN KEJADIAN KHUSUS DISTRIBUSI GAMMA
}

\section{Properties of Gamma Distribution}

\author{
Royke Yohanes Warella $^{1 *}$, Henry Junus Wattimanela ${ }^{2}$, Venn Yan Ishak Ilwaru ${ }^{3}$ \\ 1,2,3 Program Studi Matematika, Fakultas MIPA, Universitas Pattimura \\ Jl. Ir. M. Putuhena, Kampus Unpatti, Poka-Ambon, 97233, Maluku, Indonesia \\ Corresponding author e-mail: $1 *$ roykewarella@gmail.com
}

\begin{abstract}
Abstrak
Distribusi Gamma merupakan salah satu distribusi peubah acak kontinu dengan parameter skala $\alpha>0$ dan parameter bentuk $\beta>0$ dimana $\alpha, \beta$ adalah bilangan riil positif. Pada kondisi tertentu distribusi Gamma membentuk distribusi-distribusi kontinu yang lain yang kemudian disebut kejadian khusus distribusi Gamma. Oleh sebab itu, penelitian ini dilakukan untuk mengetahui sifat-sifat distribusi Gamma dan karakteristik dari kejadian khusus distribusi Gamma dengan cara analisa teori yang diperoleh dari berbagai literatur. Pembahasan distribusi Gamma meliputi nilai harapan, variansi, fungsi pembangkit momen, fungsi karakteristik, dan estimasi parameter distribusi Gamma dengan metode momen sehingga diperoleh bahwa kejadian-kejadian khusus distribusi Gamma yaitu distribusi Erlang, eksponensial, chi-kuadrat, dan beta.
\end{abstract}

Kata Kunci : Distribusi Gamma, Sifat-sifat Distribusi Gamma, Kejadian Khusus Distribusi Gamma

\begin{abstract}
The gamma distribution is one of special continuous random variable distribution with scale parameter $\alpha>0$ and shape parameter $\beta>0$ where $\alpha, \beta$ is positive real numbers. On some conditions the gamma distribution astablishes other continuous distributions which are then called special cases of the gamma distribution. Therefore, this study was conducted to determine the properties of gamma distribution and the characteristics of the special cases of gamma distribution by analyzed the theories from literatures. The properties of gamma distribution include expectation value, variance, moment generating function, characteristic function, and estimation of gamma distribution parameters with the moment method to earn the special cases of the gamma distribution are Erlang, exponential, chi-square, and beta distributions.
\end{abstract}

Keywords: Gamma Distribution, Properties of Gamma Distribution

Article info:

Received: $30^{\text {th }}$ September $2020 \quad$ Accepted: $20^{\text {th }}$ February 2021

How to cite this article:

R. Y. Warella, H. J. Wattimanela, V. Y. I. Ilwaru, "SIFAT-SIFAT DAN KEJADIAN KHUSUS DISTRIBUSI GAMMA ", BAREKENG: J. Il. Mat. \& Ter., vol. 15, no. 1, pp. 047-058, Mar. 2021.

\section{(c) () (2)}

This work is licensed under a Creative Commons Attribution-ShareAlike 4.0 International License.

Copyright () 2021 Royke Yohanes Warella, Henry Junus Wattimanela, Venn Yan Ishak Ilwaru 


\section{PENDAHULUAN}

Dalam teori peluang dan statistika distribusi peluang merupakan suatu pola yang menunjukkan besarnya peluang yang dapat diperoleh dari suatu percobaan acak. Hasil yang diperoleh pada percobaan acak tersebut merupakan suatu peubah acak yang dapat diartikan sebagai suatu fungsi dengan ruang sampel sebagai domain dan kodomainnya ialah himpunan bilangan riil. Pada suatu percobaan acak dengan ruang sampel $S$, suatu fungsi $X$ yang mengawankan setiap $s \in S$ dengan tepat satu bilangan $X(s)=x$ disebut peubah acak[8].

Suatu distribusi ditandai dengan adanya fungsi densitas yaitu suatu konsep dasar dalam statistika yang berfungsi sebagai penentu besarnya nilai peluang dalam suatu selang. Fungsi gamma merupakan salah satu komponen di dalam berbagai fungsi distribusi peluang yang teraplikasikan dalam teori peluang, statistika, dan kombinatorik [4]. Fungsi gamma diperkenalkan pertama kali oleh seorang matematikawan Swiss bernama Leonhard Euler (1707-1783) sebagai bentuk generalisasi faktorial untuk bilangan tak bulat [5]. Fungsi gamma dikenal sebagai integral Euler jenis kedua yang terdefinisi untuk suatu bilangan kompleks $z$ dengan bagian riil yang positif. Hal ini memungkinkan nilai fungsi gamma dapat ditentukan untuk suatu bilangan riil positif yang tak bulat [4].

Salah satu distribusi peluang yang terkenal dalam teori antrian dan reliabiliatas adalah distribusi Gamma, yaitu suatu distribusi peluang kontinu yang dinamai berdasarkan fungsi gamma pada fungsi densitasnya [2]. Distribusi Gamma adalah distribusi kontinu dengan dua parameter $\alpha, \beta$ yang mempengaruhi bentuk distribusi Gamma. Hal tersebut menunjukkan bahwa bentuk suatu distribusi tidak hanya ditentukan oleh peubah acak saja tetapi juga oleh parameternya. Pengaruh parameter $\alpha, \beta$ pada distribusi Gamma dapat dilihat dari perubahan yang terjadi pada distribusi Gamma. Jika parameter distribusi Gamma diberikan suatu nilai atau syarat, maka distribusi Gamma akan membentuk distribusi peluang kontinu yang lain. Distribusidistribusi yang terbentuk dari distribusi Gamma antara lain distribusi Erlang, eksponensial dan chi-kuadrat [6]. Selain itu, distribusi Beta juga merupakan distribusi yang dapat diperoleh dari distribusi Gamma [8]. Distribusi-distribusi ini kemudian disebut kejadian khusus distribusi Gamma atau keluarga distribusi Gamma.

Penelitian ini dilakukan untuk mengkaji tentang sifat-sifat dan kejadian khusus distribusi Gamma serta menemukan keterkaitan antara distribsui gamma dengan kejadian khususnya. Diharapkan penelitian ini dapat memberi suatu kajian teoritis tentang sifat-sifat dan kejadian khusus distribui gamma.

\section{METODE PENELITIAN}

Penelitian ini dilakukan dengan metode studi literatur yaitu dengan mempelajari literatur yang berkaitan dengan sifat-sifat dan kejadian khusus distribusi Gamma. Penelitian dimulai dengan menentukan topik dan judul penelitian yang diikuti dengan pengumpulan sumber pustaka. Kemudian dilanjutkan dengan mempelajari sifat-sifat dan kejadian khusus distribusi Gamma dan menambahkan grafik untuk masingmasing distribusi menggunakan program Matlab. Penelitian ini diakhiri dengan penarikan kesimpulan berdasarkan hasil penelitian.

\section{HASIL DAN PEMBAHASAN}

\subsection{Distribusi Gamma}

Suatu peubah acak kontinu $X$ dikatakan berdistribusi Gamma apabila untuk parameter $\alpha$ dan $\beta$ yang positif (ditulis $X \sim G A M(\alpha, \beta)$ ), peubah acak kontinu $X$ memiliki fungsi densitas peluang (fdp) yang berbentuk

$$
f(x ; \alpha, \beta)=\left\{\begin{array}{cc}
\frac{1}{\alpha^{\beta} \Gamma(\beta)} x^{\beta-1} e^{-\frac{x}{\alpha}} & , 0<x<\infty \\
0 & , x \text { lainnya }
\end{array}\right.
$$

Distribusi Gamma memiliki fungsi densitas kumulatif (fdk) sebagai berikut: 


$$
F(x ; \alpha, \beta)=\int_{0}^{x} \frac{1}{\alpha^{\beta} \Gamma(\beta)} t^{\beta-1} e^{-\frac{t}{\alpha}} d t
$$

Parameter $\beta$ disebut parameter bentuk dan parameter $\alpha$ disebut parameter skala apabila

$$
F(x ; \alpha, \beta)=F\left(\frac{x}{\alpha} ; 1, \beta\right)
$$

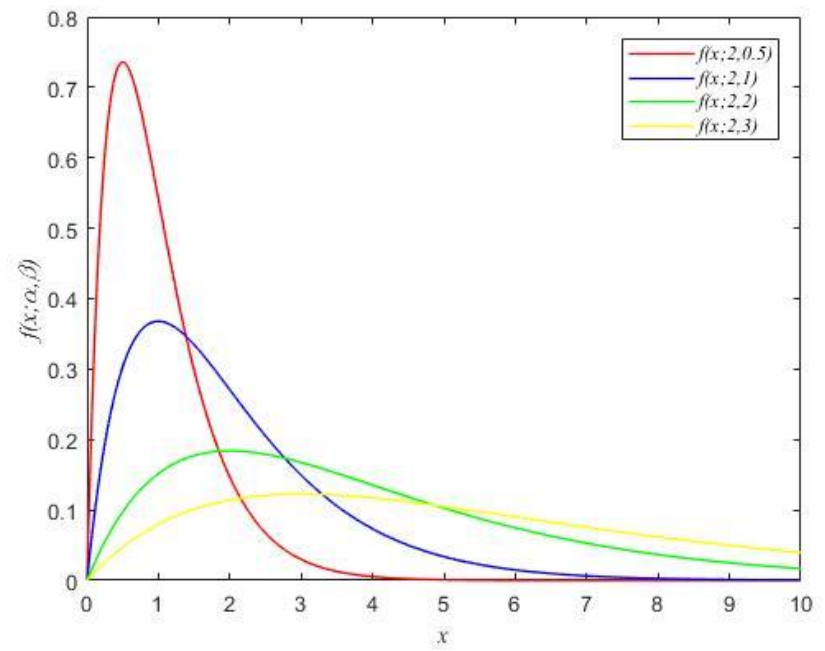

Gambar 1. Grafik fdp distribusi gamma

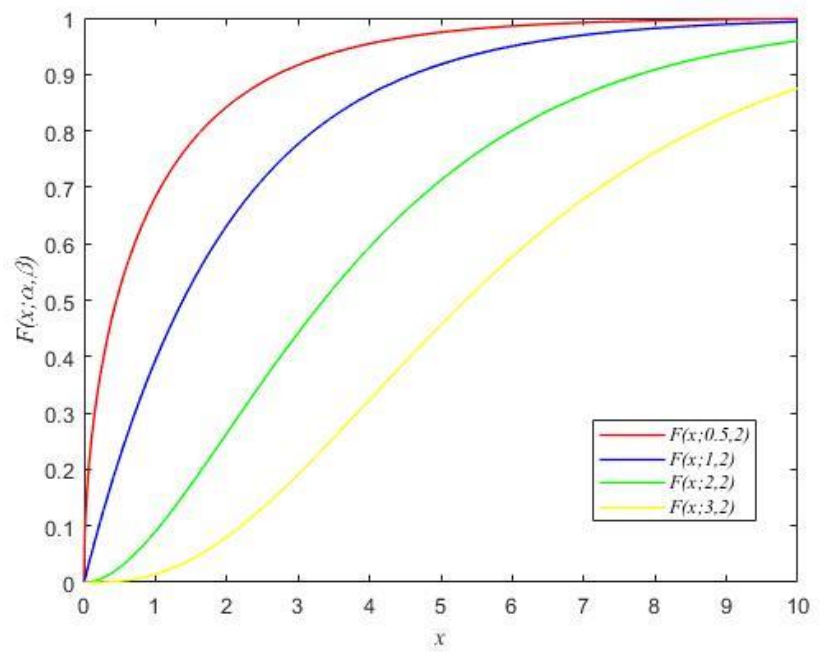

Gambar 2. Grafik fdk distribusi gamma

Pada Gambar 1 terlihat pengaruh parameter $\beta$ terhadap bentuk kurva fdp distribusi Gamma, yakni semakin kecil nilai $\beta$ maka titik puncak kurva semakin tinggi. Sedangkan Gambar 2 terlihat pengaruh parameter $\alpha$ terhadap bentuk kurva fdk distribusi Gamma, yaitu semakin kecil nilai $\alpha$ maka kurva akan semakin melengkung dan terbuka ke arah dalam. Hal ini menunjukkan bawha distribusi Gamma adalah distribusi yang positif.

\subsection{Sifat-sifat distribusi Gamma}

Sifat-sifat distribusi Gamma antara lain sebagai berikut:

\section{a. Nilai Harapan dan Variansi}

Nilai harapan untuk $X, X^{2}$, dan $X^{k}$ dari distribusi Gamma berturut-turut adalah sebagai berikut

$$
\begin{aligned}
E[X] & =\int_{-\infty}^{\infty} x f(x) d x \\
& =\int_{0}^{\infty} x \frac{1}{\alpha^{\beta} \Gamma(\beta)} x^{\beta-1} e^{-\frac{x}{\alpha}} d x
\end{aligned}
$$

misalkan $u=\frac{x}{\alpha}$ maka diperoleh $x=\alpha u$ dan $d x=\alpha d u$ sehingga

$$
\begin{aligned}
E[X] & =\int_{0}^{\infty} \frac{1}{\alpha^{\beta} \Gamma(\beta)}(\alpha u)^{\beta} e^{-u} \alpha d u \\
& =\int_{0}^{\infty} \frac{\alpha^{\beta} \alpha}{\alpha^{\beta} \Gamma(\beta)} u^{\beta} e^{-u} d u \\
& =\alpha \beta
\end{aligned}
$$




$$
\begin{aligned}
E\left[X^{2}\right] & =\int_{-\infty}^{\infty} x^{2} f(x) d x \\
& =\int_{0}^{\infty} x^{2} \frac{1}{\alpha^{\beta} \Gamma(\beta)} x^{\beta-1} e^{-\frac{x}{\alpha}} d x
\end{aligned}
$$

misalkan $u=\frac{x}{\alpha}$ maka diperoleh $x=\alpha u$ dan $d x=\alpha d u$ sehingga

$$
\begin{aligned}
E\left[X^{2}\right] & =\int_{0}^{\infty} \frac{1}{\alpha^{\beta} \Gamma(\beta)}(\alpha u)^{\beta+1} e^{-u} \alpha d u \\
& =\int_{0}^{\infty} \frac{\alpha^{\beta+1} \alpha}{\alpha^{\beta} \Gamma(\beta)} u^{\beta} e^{-u} d u \\
& =\frac{\alpha^{2}}{\Gamma(\beta)} \Gamma(\beta+2) \\
& =\alpha^{2} \beta^{2}+\alpha^{2} \beta
\end{aligned}
$$

Selanjutnya berdasarkan Persamaan (4) dan Persamaan (5) diperoleh nilai variansi distribusi Gamma sebagai berikut:

$$
\begin{aligned}
\operatorname{Var}(X) & =E\left[X^{2}\right]-(E[X])^{2} \\
& =\alpha^{2} \beta
\end{aligned}
$$

Beriktunya akan ditentukan nilai dari $E\left[X^{k}\right]$. Nilai ini ada untuk memberikan bentuk umum nilai harapan $X^{k}$ untuk sebarang $k$ yang positif, sehingga penentuan nilai harapan $X^{k}$ akan lebih mudah dilakukan tanpa harus melalui proses integral yang panjang.

$$
\begin{aligned}
E\left[X^{k}\right] & =\int_{-\infty}^{\infty} x^{k} f(x) d x \\
& =\int_{0}^{\infty} x^{k} \frac{1}{\alpha^{\beta} \Gamma(\beta)} x^{\beta-1} e^{-\frac{x}{\alpha}} d x
\end{aligned}
$$

misalkan $u=\frac{x}{\alpha}$ maka diperoleh $x=\alpha u$ dan $d x=\alpha d u$ sehingga

$$
\begin{aligned}
E\left[X^{k}\right] & =\int_{0}^{\infty} \frac{1}{\alpha^{\beta} \Gamma(\beta)}(\alpha u)^{k+\beta-1} e^{-u} \alpha d u \\
& =\int_{0}^{\infty} \frac{\alpha^{k+\beta-1} \alpha}{\alpha^{\beta} \Gamma(\beta)} u^{k+\beta-1} e^{-u} d u \\
& =\frac{\alpha^{k}}{\Gamma(\beta)} \prod_{n=1}^{k}(k+\beta-n) \Gamma(\beta) \\
& =\alpha^{k} \prod_{n=1}^{k}(k+\beta-n) \Gamma(\beta)
\end{aligned}
$$

\section{b. Fungsi Pembangkit Momen dan Fungsi Karakteristik}

Teorema 1. Misalkan $X \sim \operatorname{GAM}(\alpha, \beta)$. Fungsi pembangkit momen untuk distribusi Gamma adalah $M_{x}(t)=(1-\alpha t)^{-\beta}$. 


\section{Bukti:}

$$
\begin{aligned}
M_{x}(t) & =E\left[e^{t x}\right] \\
& =\int_{0}^{\infty} e^{t x} \frac{1}{\alpha^{\beta} \Gamma(\beta)} x^{\beta-1} e^{-\frac{x}{\alpha}} d x
\end{aligned}
$$

misalkan $u=\left(\frac{1}{\alpha}-t\right) x$ maka diperoleh $x=\frac{u}{\left(\frac{1}{\alpha}-t\right)}$ dan $d x=\frac{d u}{\left(\frac{1}{\alpha}-t\right)}$ sehingga

$$
\begin{aligned}
M_{x}(t) & =\int_{0}^{\infty} \frac{1}{\alpha^{\beta} \Gamma(\beta)}\left(\frac{u}{\frac{1}{\alpha}-t}\right)^{\beta-1} e^{-u} \frac{d u}{\frac{1}{\alpha}-t} \\
& =\frac{1}{\alpha^{\beta} \Gamma(\beta)\left(\frac{1}{\alpha}-t\right)^{\beta}} \int_{0}^{\infty} u^{\beta-1} e^{-u} d u \\
= & (1-\alpha t)^{\beta}
\end{aligned}
$$

Teorema 2. Misalkan $X \sim \operatorname{GAM}(\alpha, \beta)$. Fungsi karakteristik untuk distribusi Gamma adalah $\phi_{x}(t)=(1-\alpha i t)^{-\beta}$.

Bukti. Pembuktian Teorema 2 analog dengan pembuktian Teorema 1.

\section{c. Estimasi Parameter dengan Metode Momen}

Langkah 1. Menentukan momen pertama berdasarkan Persamaan (4)

$$
\begin{aligned}
\mu_{1} & =m_{1} \\
\alpha \beta & =\frac{1}{n} \sum_{i-1}^{n} x_{i} \\
\alpha & =\frac{\frac{1}{n} \sum_{i-1}^{n} x_{i}}{\beta}
\end{aligned}
$$

Langkah 2. Menentukan momen kedua berdasarkan Persamaan (5)

$$
\begin{aligned}
\mu_{2} & =m_{2} \\
\alpha^{2} \beta^{2}+\alpha^{2} \beta & =\frac{1}{n} \sum_{i-1}^{n} x_{i}^{2}
\end{aligned}
$$

dengan mensubtitusikan Persamaan (9) ke Persamaan (10) maka diperoleh

$$
\hat{\beta}=\frac{\frac{1}{n}\left(\sum_{i=1}^{n} x_{i}\right)^{2}}{\sum_{i=1}^{n} x_{i}^{2}-\frac{1}{n}\left(\sum_{i=1}^{n} x_{i}\right)}
$$

dengan mensubtitusikan Persamaan (11) ke Persamaan (9) maka diperoleh 


$$
\hat{\alpha}=\frac{\sum_{i=1}^{n} x_{i}^{2}-\frac{1}{n}\left(\sum_{i=1}^{n} x_{i}\right)^{2}}{\frac{1}{n} \sum_{i=1}^{n} x_{i}}
$$

Langkah 3. Menentukan momen ke- $k$ berdasarkan Persamaan (6)

$$
\begin{aligned}
\mu_{k} & =m_{k} \\
\frac{1}{n} \sum_{i=1}^{n} x_{i}^{k} & =\alpha^{k} \prod_{n=1}^{k}(k+\beta-n) \Gamma(\beta)
\end{aligned}
$$

Hasil estimasi diatas dapat disebut sebagai estimator yang baik apabila memenuhi sifat tak bias, efisien, dan konsisten.

1. Tak Bias

Berdasarkan Persamaan (4) diketahui $E[X]=\alpha \beta$ sehingga $E[X]=\hat{\alpha} \hat{\beta}=\alpha \beta$. Jadi $\hat{\alpha}, \hat{\beta}$ adalah estimator tak bias untuk $\mu$.

\section{Efisien}

Berdasarkan rumus efisiensi relatif

$$
R=\frac{\operatorname{Var}\left(X_{1}\right)}{\operatorname{Var}\left(X_{2}\right)}=\frac{\hat{\alpha}_{1}^{2} \hat{\beta}_{1}}{\hat{\alpha}_{2}^{2} \hat{\beta}_{2}}
$$

diperoleh Jika $R>1$ maka $\hat{\alpha}_{1}^{2} \hat{\beta}_{1}>\hat{\alpha}_{2}^{2} \hat{\beta}_{1}$. Artinya $\operatorname{Var}\left(X_{1}\right)>\operatorname{Var}\left(X_{2}\right)$ sehingga penduga $\hat{\alpha}_{1,} \hat{\beta}_{1}$ lebih efisien dibandingkan dengan $\hat{\alpha}, \hat{\beta}_{2}$.

\section{Konsisten}

Suatu penduga atau estimator disebut sebagai penduga yang konsisten apabila $\mathrm{E}[\hat{\theta}-E[\theta]]^{2} \rightarrow 0$ untuk $n \rightarrow \infty$, sehingga untuk peubah acak $X$ yang berdistribusi Gamma dengan parameter $\alpha, \beta$ tidak diketahui, dapat ditulis $\mathrm{E}[\hat{\alpha} \hat{\beta}-E[\alpha \beta]]^{2} \rightarrow 0$ untuk $n \rightarrow \infty$. Karena $\mathrm{E}[\hat{\alpha} \hat{\beta}-E[\alpha \beta]]^{2}$ akan mendekati nol untuk $n$ menuju tak hingga maka nilai dari $\lim _{n \rightarrow \infty} \mathrm{E}[\hat{\alpha} \hat{\beta}-E[\alpha \beta]]^{2}=0$. Oleh sebab itu, $\hat{\alpha}, \hat{\beta}$ disebut penduga yang konsisten untuk $\alpha, \beta$.

Karena hasil estimasi distribusi Gamma memenuhi sifat tak bias, efisien, dan konsisten maka hasil estimasi di atas dapat disebut sebagai estimator yang baik.

\subsection{Kejadian-kejadian Khusus Distribusi Gamma}

Kejadian khusus distribusi Gamma adalah distribusi-distribusi yang terbentuk akibat perubahan yang terjadi pada parameter distribusi Gamma. Kejadian khusus distribusi Gamma antara lain, sebagai berikut:

\section{a. Distribusi Erlang}

Distribusi Erlang ialah kondisi khusus distribusi Gamma yaitu ketika parameter $\beta$ pada distribubsi gamma hanya boleh bilangan bulat positif. Hal ini mengakibatkan distribusi Erlang memiliki sifat -sifat yang sama persis dengan distribusi Gamma. Karena kedekatannya, kurva distribusi Erlang juga mengikut kurva distribus gamma yang dapat terlihat pada Gambar 3. Pada gambar, distribusi Erlang terlihat mengikuti bentuk distribuis chi-kuadrat pada saat $f(x ; 1,2)$. Kondisi ini menunjukkan adanya hubungan antara distribusi Erlang dan chi-kuadrat. 


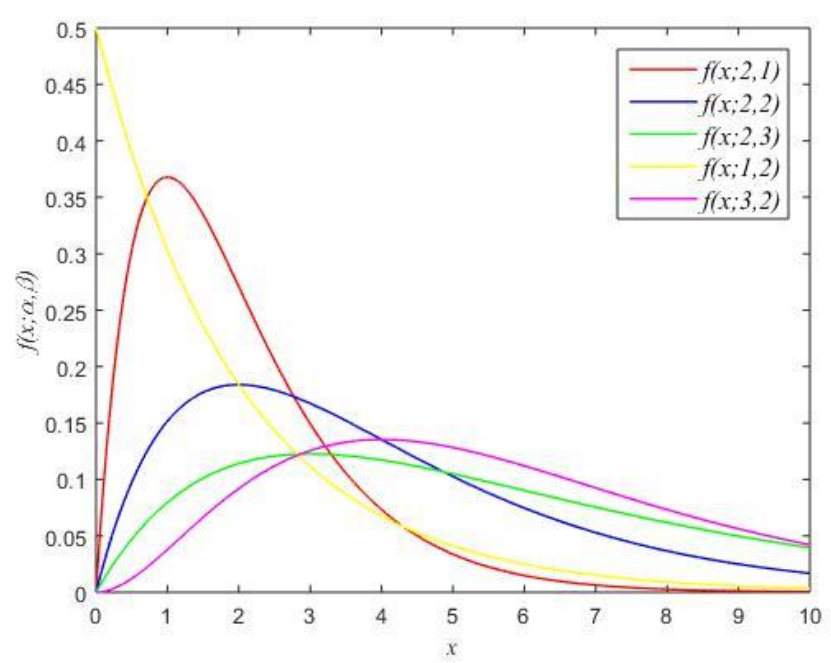

Gambar 3. Grafik fdp distribusi Erlang

\section{b. Distribusi Eksponensial}

Suatu peubah acak kontinu $X$ yang berdistribusi Eksponensial ditulis $X \sim \operatorname{EXP}(\alpha)$. Distribusi Eksponensial sendiri merupakan kejadian khusus distribusi Gamma dengan parameter $\beta=1$, oleh sebab itu berdasarkan Persamaan (1) maka fdp distribusi Eksponensial adalah

$$
f(x, \alpha)=\left\{\begin{array}{cl}
\frac{1}{\alpha} e^{-\frac{x}{\alpha}} & , \alpha \text { positif } ; 0<x<\infty \\
0 & , x \text { lainnya }
\end{array}\right.
$$

Karena distribusi Eksponensial ialah kejadian khusus distribusi Gamma dengan parameter $\beta=1$, maka berdasarkan Persamaan (4), Persamaan (5), Persamaan (6) dan Persamaan (7) diperoleh

$$
\begin{aligned}
& E[X]=\alpha \\
& E\left[X^{2}\right]=2 \alpha^{2} \\
& E\left[X^{k}\right]=\alpha^{k} \prod_{n=1}^{k} k+1-n \\
& \operatorname{Var}(X)=\alpha^{2}
\end{aligned}
$$

Kemudian, berdasarkan Teorema 1 dan Teorema 2, maka fungsi pembangkit momen dan fungsi karakteristik distribusi Eksponensial adalah $M_{x}(t)=(1-\alpha t)^{-1}$ dan $\phi_{x}(t)=(1-\alpha i t)^{-1}$.

Gambar 4 adalah contoh kurva dari fdp distribusi Eksponensial. Gambar ini menunjukkan sifat eksponensial yang nilainya mendekati nol tapi tidak akan pernah sama dengan no. Terlihat pada gambar di bawah kurva distribusi Eksponensial saling berpotongan di satu titik pada $\alpha \geq 3$. Hal ini berarti pada satu titik $x$, untuk sebarang $\alpha \geq 3$ diperoleh nilai distribusi Eksponensial yang sama. Kurva $f(x, 1)$ adalah kurva fungsi eksponensial. 


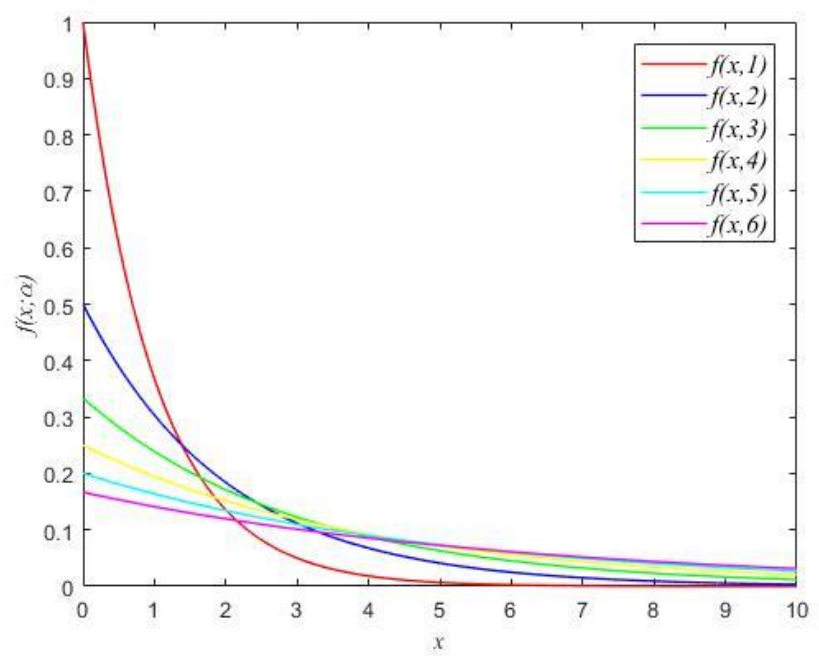

Gambar 4. Grafik fdp distribusi Eksponensial

\section{c. Distribusi Chi-Kuadrat}

Distribusi Chi-Kuadrat adalah distribusi Gamma dengan parameter $\alpha=2$ dan $\beta=\frac{v}{2}$ dimana $v$ bilangan asli.Distribusi Chi-Kuadrat memiliki parameter tunggal $v$ yang disebut derajat bebas. Suatu peubah acak $X$ yang berdistribusi Chi-Kuadrat (ditulis : $X \sim \chi^{2}(v)$ ) memiliki fdp sebagai berikut

$$
f(x ; v)=\left\{\begin{array}{cc}
\frac{1}{2^{\frac{v}{2}} \Gamma\left(\frac{v}{2}\right)} x^{\frac{v}{2}-1} e^{-\frac{x}{2}} & , 0<x<\infty \\
0 & , x \text { lainnya }
\end{array}\right.
$$

Karena distribusi Chi-Kuadrat ialah kejadian khusus distribusi Gamma dengan $\alpha=2$ dan $\beta=\frac{v}{2}$ maka berdasarkan Persamaan (4), (5), (6), dan (7) diperoleh:

$$
\begin{aligned}
& E[X]=v \\
& E\left[X^{2}\right]=v^{2}+2 v \\
& E\left[X^{k}\right]=2^{k} \prod_{n=1}^{k} k+\frac{v}{2}-n \\
& \operatorname{Var}(X)=2 v
\end{aligned}
$$

Berdasarkan Teorema 1 dan Teorema 2 maka fungsi pembangkit momen dan fungsi karakteristik untuk distribusi Chi-Kuadrat adalah $M_{x}(t)=(1-2 t)^{-\frac{v}{2}}$ dan $\phi_{x}(t)=(1-2 i t)^{-\frac{v}{2}}$. 

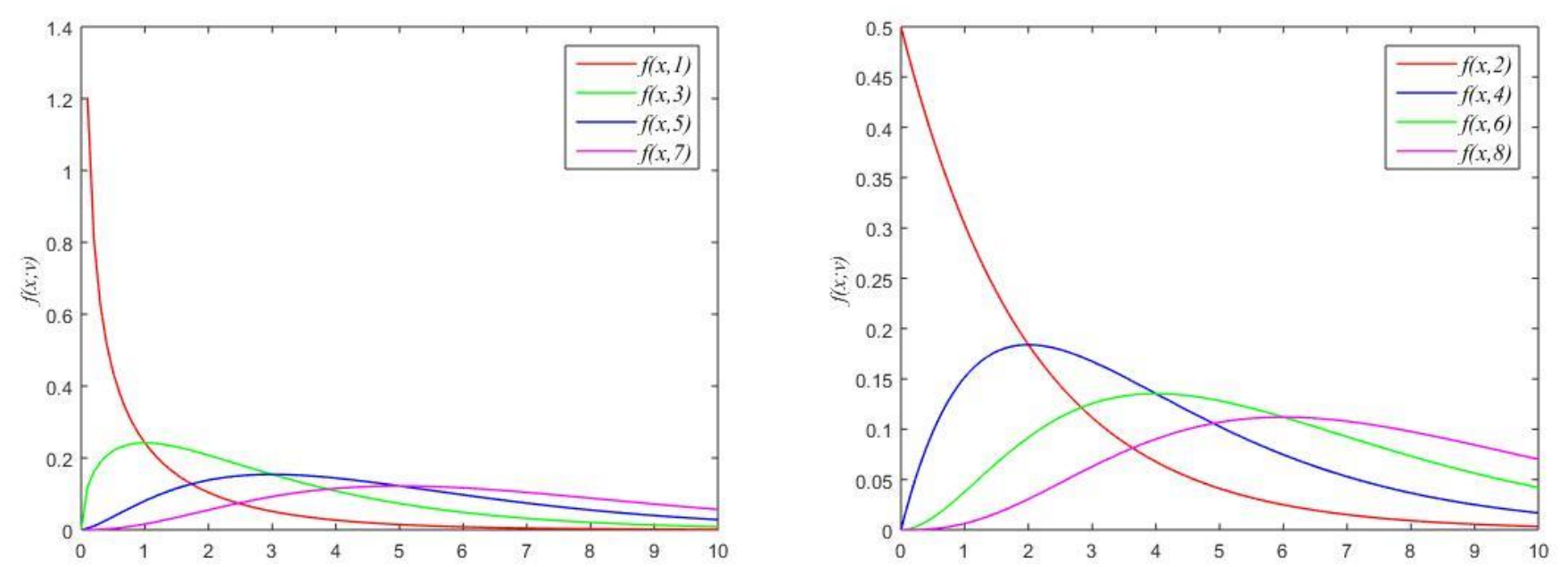

Gambar 5. Grafik fdp distribusi Chi-Kuadrat untuk $v$ ganjil Gambar 6. Grafik fdp distribusi Chi-Kuadrat untuk $v$ genap

Pada gambar di bawah ini, menunjukkan bahwa pada dasarnya grafik distribusi Chi-Kuadrat bergantung pada derajat bebas $v$. Pada Gambar 5 dan Gambar 6 terlihat bahwa pada $v \geq 3$ distribusi ChiKuadrat mendekati distribusi normal dan mendekati distribusi Eksponensial pada $v=2$. Sedangkan pada saat $v=1$, distribusi Chi-Kuadrat disebut berdistribusi normal kuadrat standar.

\section{d. Distribusi Beta}

Misalkan $X$ suatu peubah acak kontinu. $X$ dikatakan berdistribusi Beta (ditulis : $X \sim \operatorname{BETA}(\alpha, \beta)$ ) apabila memiliki fdp berbentuk

$$
f(x: \alpha, \beta)=\left\{\begin{array}{cc}
\frac{\Gamma(\alpha+\beta)}{\Gamma(\alpha) \Gamma(\beta)} x^{\alpha-1}(1-x)^{\beta-1} & , 0<x<1 \\
0 & , x \text { lainnya }
\end{array}\right.
$$

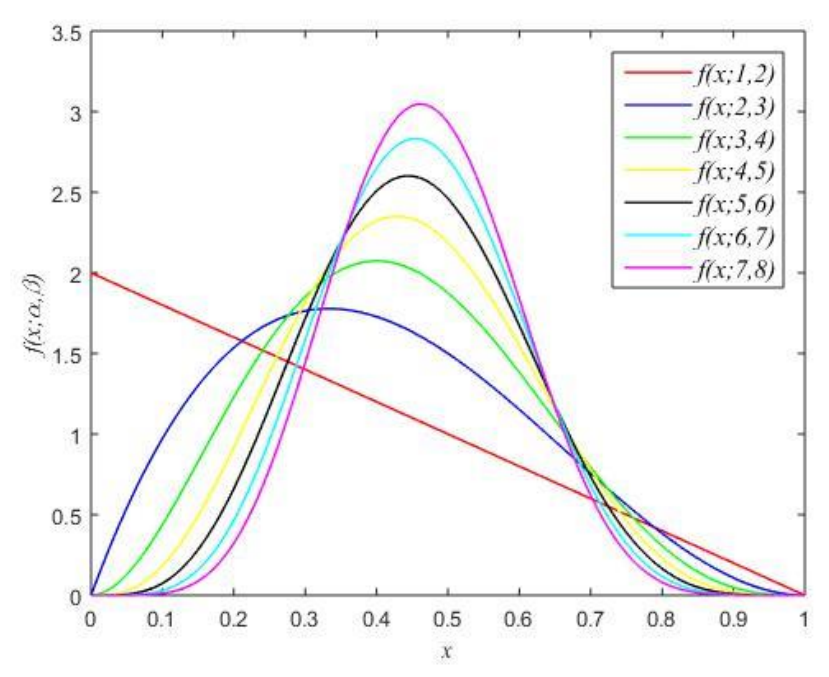

Gambar 5. Grafik fdp distribusi Beta

Gambar 7 menunjukkan grafik distribusi Beta yang dipengaruhi dua parameter $\alpha, \beta$. Terlihat bahwa semakin besar nilai $\alpha, \beta$ maka kurva distribusi Beta akan semakin ramping dan titik puncak kurva semakin tinggi. Kejadian khusus distribusi Beta pada $f(x ; 1,2)$ dimana distribusi Beta membentuk persamaan garis lurus.

Keterkaitan antara distribusi Gamma dan distribusi Beta dijelaskan di bawah ini. 
Misalkan $X_{1} \sim \operatorname{GAM}(1, \alpha)$ dan $X_{2} \sim \operatorname{GAM}(1, \beta)$ dimana $X_{1}, X_{2}$ saling bebas. Berdasarkan Persamaan (1) maka fdp bersama untuk $X_{1}, X_{2}$ ialah

$$
h\left(x_{1}, x_{2}\right)=\frac{1}{\Gamma(\alpha) \Gamma(\beta)} x_{1}^{\alpha-1} x_{2}^{\beta-1} e^{-\left(x_{1}+x_{2}\right)}
$$

Dengan menggunakan transformasi $Y_{1}=X_{1}+X_{2}$ dan $Y_{2}=\frac{X_{1}}{X_{1}+X_{2}}$ maka $X_{1}=Y_{1} Y_{2}$ dan $X_{2}=Y_{1}\left(1-Y_{2}\right)$, sehingga diperoleh nilai Jacobian $\boldsymbol{J}=-Y_{1}$. Selanjutnya berdasarkan transformasi beberapa peubah acak diperoleh fdp bersama untuk $Y_{1}, Y_{2}$ yaitu

$$
g\left(y_{1}, y_{2}\right)=\frac{y_{2}^{\alpha-1}\left(1-y_{2}\right)^{\alpha-1}}{\Gamma(\alpha) \Gamma(\beta)} y_{1}^{\alpha+\beta-1} e^{-y_{1}}
$$

Berdasarkan Persamaan (18) maka diperoleh fdp marginal masing-masing untuk $Y_{1}$ dan $Y_{2}$ berturut-turut

$$
\begin{aligned}
g_{1}\left(y_{1}\right) & =\int_{-\infty}^{\infty} g\left(y_{1}, y_{2}\right) d y_{2} \\
& =\int_{0}^{\infty} \frac{y_{2}^{\alpha-1}\left(1-y_{2}\right)^{\beta-1}}{\Gamma(\alpha) \Gamma(\beta)} y_{1}^{\alpha+\beta-1} e^{-y_{1}} d y_{2} \\
& =\frac{y_{1}^{\alpha+\beta-1} e^{-y_{1}}}{\Gamma(\alpha+\beta)} \\
g_{2}\left(y_{2}\right) & =\int_{-\infty}^{\infty} g\left(y_{1}, y_{2}\right) d y_{1} \\
& =\int_{0}^{\infty} \frac{y_{2}^{\alpha-1}\left(1-y_{2}\right)^{\beta-1}}{\Gamma(\alpha) \Gamma(\beta)} y_{1}^{\alpha+\beta-1} e^{-y_{1}} d y_{2} \\
& =\frac{\Gamma(\alpha+\beta)}{\Gamma(\alpha) \Gamma(\beta)} y_{2}^{\alpha-1}\left(1-y_{2}\right)^{\beta-1}
\end{aligned}
$$

Berdasarkan Persamaan (19) dan Persamaan (20) dapat diketahui bahwa $Y_{1} \sim G A M(1, \alpha+\beta)$ dan $Y_{2} \sim \operatorname{BETA}(\alpha, \beta)$.

Berikut ini secara berurutan adalah nilai harapan untuk $X, X^{2}, X^{k}$ distribusi Beta, yaitu

$$
\begin{aligned}
E[X] & =\int_{-\infty}^{\infty} x f(x) d x \\
& =\frac{1}{B(\alpha, \beta)} \int_{0}^{1} x^{\alpha}(1-x)^{\beta-1} d x \\
& =\frac{\alpha}{\alpha+\beta} \\
E\left[X^{2}\right] & =\int_{-\infty}^{\infty} x^{2} f(x) d x \\
& =\frac{1}{B(\alpha, \beta)} \int_{0}^{1} x^{\alpha+1}(1-x)^{\beta+1} d x
\end{aligned}
$$




$$
\begin{aligned}
& =\frac{\alpha(\alpha+1)}{(\alpha+\beta+1)(\alpha+\beta)} \\
E\left[X^{k}\right] & =\int_{-\infty}^{\infty} x^{k} f(x) d x \\
& =\frac{1}{B(\alpha, \beta)} \int_{0}^{1} x^{(\alpha+k)-1}(1-x)^{\beta-1} d x \\
& =\frac{B((\alpha+k), \beta)}{B(\alpha, \beta)} \\
& =\frac{\Gamma(\alpha+\beta) \Gamma(\alpha+k) \Gamma(\beta)}{\Gamma(\alpha) \Gamma(\beta) \Gamma(\alpha+\beta+k)} \\
& =\frac{\alpha \times(\alpha+1) \times \cdots \times(\alpha+k-1)}{(\alpha+\beta) \times(\alpha+\beta+1) \times \cdots \times(\alpha+\beta+k-1)} \\
& =\prod_{n=0}^{k-1} \frac{\alpha+n}{\alpha+\beta+n} \quad \mathbf{\square}
\end{aligned}
$$

Selanjutnya berdasarkan Persamaan (22) dan (23) maka variansi untuk distribusi Beta adalah sebagai berikut:

$$
\begin{aligned}
\operatorname{Var}(X) & =E\left[X^{2}\right]-(E[X])^{2} \\
& =\frac{\alpha \beta}{(\alpha+\beta+1)(\alpha+\beta)^{2}}
\end{aligned}
$$

Teorema 3. Suatu peubah acak X berdistribusi Beta dengan $f d p f(x)$. Fungsi pembangkit momen untuk distribusi Beta diberikan oleh:

Bukti.

$$
M_{x}(t)=\sum_{k=0}^{\infty} \frac{t^{k}}{k !} \frac{B(\alpha+k, \beta)}{B(\alpha, \beta)}=1+\sum_{k=1}^{\infty} \frac{t^{k}}{k !} \prod_{n=0}^{k-1} \frac{\alpha+n}{\alpha+\beta+n}
$$

$$
\begin{aligned}
M_{x}(t) & =E\left[e^{t x}\right] \\
& =\int_{-\infty}^{\infty} e^{t x} f(x) d x \\
& =\frac{1}{B(\alpha, \beta)} \int_{0}^{1} e^{t x} x^{\alpha-1}(1-x)^{\beta-1} d x \\
& =\frac{1}{B(\alpha, \beta)} \int_{0}^{1}\left(\sum_{k=0}^{\infty} \frac{(t x)^{k}}{k !}\right) x^{\alpha-1}(1-x)^{\beta-1} d x \\
& =\frac{B(\alpha+k, \beta)}{B(\alpha, \beta)} \sum_{k=0}^{\infty} \frac{(t x)^{k}}{k !} \\
& =1+\sum_{k=1}^{\infty} \frac{(t x)^{k}}{k !} \prod_{n=0}^{\infty} \frac{\alpha+n}{\alpha+\beta+n}
\end{aligned}
$$

Teorema 4. Suatu peubah acak X berdistribusi Beta dengan $f d p f(x)$. Fungsi karakteristik untuk distribusi Beta diberikan oleh

$$
\phi_{x}(t)=\sum_{k=0}^{\infty} \frac{i t^{k}}{k !} \frac{B(\alpha+k, \beta)}{B(\alpha, \beta)}=1+\sum_{k=1}^{\infty} \frac{i t^{k}}{k !} \prod_{n=0}^{k-1} \frac{\alpha+n}{\alpha+\beta+n}
$$

Bukti. Pembuktian Teorema 4 analog dengan pembuktian Teorema 3. 


\section{KESIMPULAN}

Berdasarkan hasil yang telah diperoleh maka dapat disimpulkan bahwa keterkaitan distribusi Gamma dengan kejadian khususnya adalah:

a. Distribusi Erlang adalah distribusi Gamma dengan syarat khusus yaitu parameter $\beta$ hanya boleh bilangan bulat positif

b. Distribusi Eksponensial adalah distribusi Gamma dengan parameter $\beta=1$.

c. Distribusi Chi-Kuadrat adalah distribusi Gamma dengan parameter $\alpha=2$ dan $\beta=\frac{v}{2}$ dimana $v$ bilangan asli. Distribusi Chi-Kuadrat memiliki parameter tunggal $v$ yang disebut derajat bebas

d. Distribusi Beta adalah disttribusi kontinu yang dapat dibangun dari dua pubah acak kontinu $X_{1} \sim \operatorname{GAM}(1, \alpha)$ dan $\quad X_{2} \sim \operatorname{GAM}(1, \beta) \quad$ yang membentuk $Y=\frac{X_{1}}{X_{1}+X_{2}}$ sehingga $Y \quad$ disebut berdistribusi Beta dengan parameter $(\alpha, \beta)$.

\section{DAFTAR PUSTAKA}

[1] A. Lutfi, Pendugaan Parameter Distribusi Erlang Menggunakan Metode Probability Weigthed Moment, Method of Momen, dan Maximum Likelihood Estimator, S.Si [Skripsi]. Bandar Lampung, Lampung : Universitas Lampung, 2017. [Online]. Tersedia : Digital Library Universitas Lampung.

[2] A. S. Nasution, Estimasi Parameter dan Pengujian Hipotesis Pada Model Regresi Gamma (Studi Kasus: Pemodelan Pencemaran Air Sungai di Surabaya), M.si [Tesis]. Padangsidipuan, Sumatera Utara : Universitas Graha Nusantara Padangsidipuan, 2018. [Online]. Tersedia : Universitas Graha Nu [1]santara Padangsidipuan - Jurnal Paidagogeo.

[3] F. Ridiani. "Pendugaan Parameter Distribusi Beta dengan Metode Momen dan Metode Maksimum Likelihhod," Jurnal Matematika UNAND, vol. 3, no. 2, pp. 23 - 28, 2014.

[4] James Bonnar, “The Gamma Function”, Treasure Trove of Mathematics, 2017, [Online]. Tersedia: Semantic Scholar.

[5] J.M. Borwein and R. M. Corless,"Gamma and Factorial in the Monthly," arXiv, 15 Maret 2017, [Online]. Tersedia: https://arxiv.Org/abs /1703.05349 [Diakses: 20 Agustus 2020].

[6] R. Kurniasih dan G. Pramesti. "Distribusi Erlang dan Penerapannya," Prosiding Konferensi Nasional Penelitian Matematika dan Pembelajarannya, pp . 223 - 236, 15 Mei, 2013.

[7] R. S. Taringan, Kajian Parameter Berdistribusi Gamma dengan Moments Method dan Maximum Likelihood Estimator, S.Si [Skripsi]. Medan, Sumatera Utara : Universitas Sumatera Utara, 2015. [Online]. Tersedia : Repository USU.

[8] R. V. Hoog, J. W. McKean, and A. T. Craig, Introduction to Mathematical Statistics, $7^{\text {th }}$ Edition, Boston, Pearson Education, Inc., 2013.

[9] R. Yendra dan E. T. Noviadi, “Perbandingan Estimasi Parameter Pada Distribusi Eksponensial Dengan Menggunakan Metode Maksimum Likelihhod dan Metode Bayesian,” Jurnal Sains Matematika dan Statistik, vol. 1, no. 2, pp. 62 - 72, Juli 2015.

[10] Sugito dan M. A. Mukid. "Distribusi Poisson dan Distribusi Eksponensial dalam Proses Stokastik," Media Statistika, vol. 4, no. 2, pp. 113 - 120. Desember 2011.

[11] U. Hasanah, P. Yanuar, dan D. Devianto, "Pendugaan Parameter Pada Distribusi Gamma Dengan Metode Bayes," Jurnal Matematika UNAND, vol. 7, no. 4, pp. 81 - 86, Desember 2018 